\title{
Tree ring-based February-April temperature reconstruction for Changbai Mountain in Northeast China and its implication for East Asian winter monsoon
}

\author{
H. F. Zhu ${ }^{1,2}$, X. Q. Fang ${ }^{2}$, X. M. Shao ${ }^{1}$, and Z. Y. Yin ${ }^{3}$ \\ ${ }^{1}$ Institute of Geographic Sciences and Natural Resources Research, Chinese Academy of Sciences, Beijing, China \\ ${ }^{2}$ School of Geography, Beijing Normal University, Beijing, China \\ ${ }^{3}$ Dept. of Marine Science and Environmental Studies, University of San Diego, San Diego, USA
}

Received: 27 March 2009 - Published in Clim. Past Discuss.: 15 April 2009

Revised: 6 September 2009 - Accepted: 8 September 2009 - Published: 30 October 2009

\begin{abstract}
Long-term climatic records are scarce in the northeast Asia for understanding the behavior of the East Asian Winter Monsoon. Here we describe a 250-year February-April temperature reconstruction (TCBM) based on tree-ring widths of Korean Pines from the Changbai Mountain area, Northeast China. The reconstruction can account for $45.7 \%$ of the temperature variance in the instrumental period (1953 to 2001). Four cold periods including 1784-1815, 1827-1851, 1878-1889 and 1911-1945, and two warm periods of $1750-1783$ and $1855-1877$ were identified before the instrumental period. Four shifts were also detected at 1781, 1857, 1878 and 1989. Good agreements between TCBM and other temperature records of East Asia suggest that the reconstruction is of good reliability and captures the regional cold/warm periods of East Asia. Moreover, TCBM shows negative correlations with the instrumental or proxy-based EAWM intensity records. The known weakening of the EAWM in the late 1980s is in agreement with the shift at 1989 in TCBM. These comparisons suggest that the February-April temperature reconstruction may be a good indicator of the EAWM intensity.
\end{abstract}

\section{Introduction}

Long temperature records are critical in studying the longterm behavior of the East Asian Winter Monsoon (EAWM), which is a key climatological feature in the northern hemisphere winter. Tree rings, as a continuously and annually resolved proxy, have been widely used to reconstruct past climate in North America and Europe (e.g., Briffa et al., 2004;

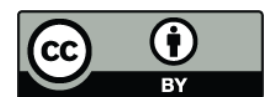

Correspondence to: X. Q. Fang

(xfang@bnu.edu.cn)
Cook et al., 1999). In recent years, there are also several dendroclimatic reconstructions in East Asia (EA), such as in China, Korea and Japan (e.g., Choi et al., 1994; Shao and Wu, 1997; Yonenobu and Eckstein, 2006; Zhu et al., 2008). However, there still remains a lack of long temperature proxies for the northeast Asia, where winter climate is predominantly influenced by the intensity of the EAWM.

The purpose of this study is to reconstruct winter temperature based on tree-ring widths of Korean Pines from the Changbai (also known as Baekdu) Mountain area in Northeast China (Fig. 1). This reconstruction may also be useful for studying the long-term behavior of the EAWM.

\section{Materials and methods}

The study area is located in the Changbai Mountain, a volcano in Northeast China, where the climate is affected by the East Asian monsoon (Fig. 1). At the meteorological station in Dunhua $\left(43^{\circ} 22^{\prime} \mathrm{N}, 128^{\circ} 12^{\prime} \mathrm{E}, 52 \mathrm{~m}\right.$ a.s.l.), January (mean temperature of $-16.9^{\circ}$ ) and July $\left(19.9^{\circ}\right.$ ) are the coldest and the warmest month, respectively (Fig. 2). The multiyear mean of annual precipitation amounts to $630 \mathrm{~mm}$, with $88.4 \%$ of the annual precipitation falling during the growing season approximately from April to September.

Tree-ring increment cores were sampled from four sites of trees in the Changbai Mountain (Table 1). The trees sampled were all from the dominant species, Korean Pine (Pinus koraiensis), of closed-canopy temperate forest. The cores were mounted, crossdated and measured through traditional process (Fritts, 1976; Stokes and Smiley, 1968). Then we used the COFECHA program to evaluate the accuracy of the crossdating and measurements (Holmes, 1983).

Published by Copernicus Publications on behalf of the European Geosciences Union. 


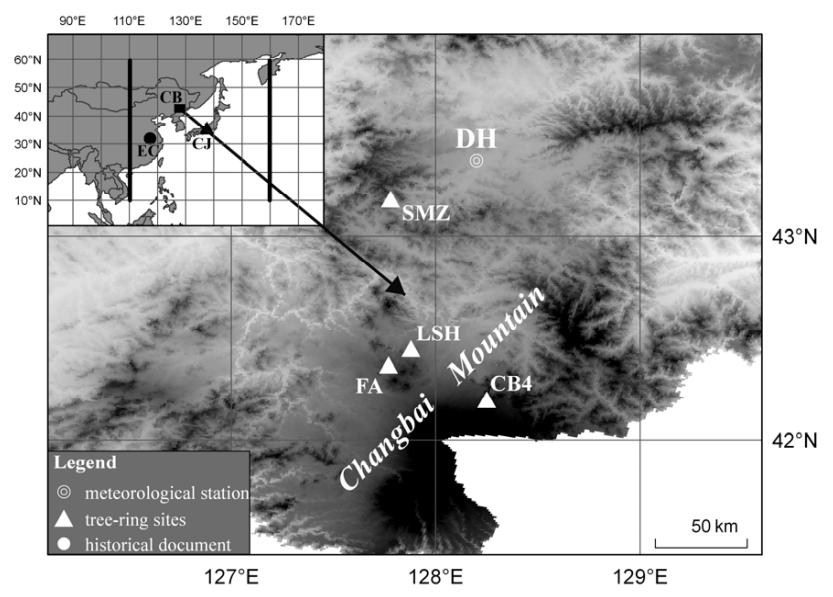

Fig. 1. Map showing the tree-ring sites, meteorological station, and other locations mentioned in text. CJ: Feburary-April temperature (Yonenobu and Eckstein, 2006); EC: Winter-half year temperature (Ge et al., 2003). The grids for the EAWMI are marked by the solid bars in the panel upper left.

Table 1. Site information and tree-ring chronology statistics ${ }^{\mathrm{a}}$.

\begin{tabular}{lccccccccc}
\hline Site & Lat & Lon & Elev & TS & MSL & C/T & Ac1 & Rbt & Y $_{\text {EPS }>0.85}$ \\
\hline CB4 & $42^{\circ} 12^{\prime}$ & $128^{\circ} 15^{\prime}$ & 1188 & $1651-2002$ & 229 & $27 / 14$ & 0.461 & 0.260 & 1810 \\
LSH & $42^{\circ} 27^{\prime}$ & $127^{\circ} 53^{\prime}$ & 870 & $1743-2002$ & 180 & $40 / 21$ & 0.349 & 0.338 & 1825 \\
FA & $42^{\circ} 22^{\prime}$ & $127^{\circ} 46^{\prime}$ & 940 & $1689-2002$ & 206 & $40 / 27$ & 0.444 & 0.251 & 1765 \\
SMZ & $43^{\circ} 11^{\prime}$ & $127^{\circ} 47^{\prime}$ & 765 & $1742-2002$ & 199 & $57 / 29$ & 0.531 & 0.232 & 1800 \\
\hline
\end{tabular}

a Lat=site latitude; Lon=site longtitude; Elev=site elevation in meters; TS=time span; MSL=median segment length; $\mathrm{C} / \mathrm{T}=$ number of cores/trees; Ac1=first order autocorrelation; Rbt=correlation between trees; $\mathrm{Y}_{\mathrm{EPS}>0.85}=\mathrm{year}$ of $\mathrm{EPS}>0.85$.

Tree-ring chronologies were developed using the ARSTAN program. A 180-year cubic smoothing spline was used to remove the long-term growth trends of raw ringwidth series. The resulting ratio series were then averaged to build the site chronologies. To evaluate the reliability of the chronologies, the 50-year moving Expressed Population Signal (EPS) with a 25-year lag (Wigley et al., 1984) was calculated (Table 1). Significant correlations from 0.52 to 0.63 exist among all site chronologies over the 1825-2002 common period (EPS $>0.85$ ). This allowed us to build a regional chronology $(\mathrm{CB})$ by averaging all the individual ratio series of the four sites. CB is considered to be reliable after $1750 \mathrm{AD}$, when the sample depth is 20 series, although the EPS is 0.80 , slightly lower than the commonly used level of 0.85 .

The relationships between tree-ring indices and climate variables were analyzed using correlation analysis for the period 1953-2002. The climate variables include monthly mean temperature and total precipitation from the Dunhua meteorological station (Fig. 1). The data from previous Oc-

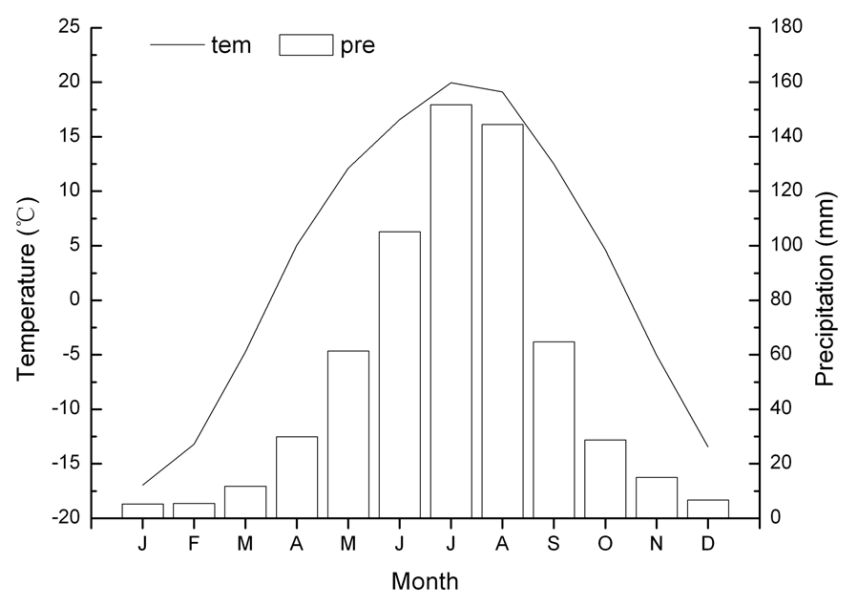

Fig. 2. Climate diagrams (1953-2002) at the Dunhua meteorological station.

tober to current October were used for the analysis, as the climate conditions of the previous year may have effects on tree-ring growth of the current year (Fritts, 1976).

To reconstruct the past climate variations, the instrumental records were regressed against the regional chronology (CB). In consideration of the lag effects of climate on tree growth, concurrent chronologies (at $t$ ) and those lagged at $t+1$ were used as independent variables. Several seasonal mean temperature subsets were examined from previous October to current September according to results of correlation analysis (Fig. 3). The leave-one-out cross-validation method (Michaelsen, 1987) was used to choose the most successful season, since the instrumental data set from 1953-2002 was too short to be divided into two subsets for independent calibration and verification tests. The testing statistics include variance explained, adjusted variance explained, sign test of the first difference (SN1), sign test of the raw data (SN2), the reduction of error (RE) and Pearson's correlation coefficient (Fritts, 1976; Cook and Kairiukstis, 1990).

\section{Results}

Figure 3 illustrates the correlation coefficients between the regional chronology $(\mathrm{CB})$ and the monthly climate data. Ring width shows significantly $(p<0.01)$ positive correlations with the temperature in previous October, current February to April, and September. However, there were no significant correlations between CB and precipitation.

The transfer function between February-April temperature and tree-ring chronologies ( $t$ and $t+1)$ acquired the best calibration and cross-validation statistics (Table 2). The final calibration model $\left(\mathrm{Tem}=-10.9+2.35 \mathrm{CB}_{t}+4.12 \mathrm{CB}_{t+1}\right)$ explained $46.2 \%$ of the total variance of the instrumental 
records during 1953-2002 (Fig. 4), and 37.1\% in the leaveone-out cross validation. The positive RE indicates good predictive skill of the regression model. The lower SN1 and highest SN2 suggest that the strength of the calibration lies more in the lower-frequency agreement between the reconstruction and the instrumental records.

Figure 5a shows the interannual to multi-decadal variations of the reconstructed February-April temperature (TCBM) for the Changbai Mountain area since 1750. Several extended warm and cold periods ( $>11$ years) were identified before the instrumental period (1953-2002) according to the 11-year moving averages of the reconstruction and the longterm mean $\left(1750-2002,-4.05^{\circ}\right)$. Warm periods occurred around 1750-1783 (W1) and 1855-1877 (W2), while cold periods at 1784-1815 (C1), 1827-1851 (C2), 1878-1889 (C3), and 1911-1945 (C4) (Fig. 5a). Intervention analysis (Rodionov, 2004), with the mean values of 15 -year periods being compared with values on either side of each year, was also applied to the TCBM to identify any significant shifts $(p<0.05)$ (Fig. 5a). Four shifts were identified at 1781, 1857, 1878 and 1989.

\section{Discussion}

The results of correlation analysis (Fig. 3) suggest that the radial growth of Korean Pine in Changbai Mountain is mainly limited by the pre-growth season temperature. A positive effect of winter temperature on tree growth was also reported for other temperate coniferous forests, such as in central Japan and in the Hudson River Valley (Pederson et al., 2004; Yonenobu and Eckstein, 2006), and from timberline forests on the east and northeast Tibetan Plateau (Brauning, 2001; Liang et al., 2009; Liu et al., 2007; Zhu et al., 2008). Warm winters may lead to damage to the roots and positive carbon gains for conifer trees when their leaves are not frozen (Brauning, 2001; Chabot and Hicks, 1982; Havranek and Tranquillini, 1995; Pederson et al., 2004). In addition, the warmer temperature of previous October may allow an extended period of carbon accumulation for the growth of next year. However, the positive effect of current September is difficult to interpret because the cell division and enlargement have probably ceased at the end of the growing season (April-September).

Our winter temperature reconstruction captures a warming trend in the recent decades in northeast China. A warming trend in winter was also recorded by tree growth on the Tibetan Plateau (Liu et al., 2007; Zhu et al., 2008; Shao and Fan, 1999). However, a study based on tree-ring width in central Japan (Yonenobu and Eckstein, 2006) did not track such a warming trend, probably due to the consequence of anthropogenic $\mathrm{SO}_{2}$ emissions. Increased summer temperatures were recorded by tree growth in other areas of EA, such as Mongolia (D'Arrigo et al., 2000), central Korea (Choi et al., 1994) and Tibetan Plateau (Liang et al., 2008). Un-
Table 2. The calibration and verification statistics of different seasonal temperature models. The leave-one-out method was used for verification during the period of 1953-2001

\begin{tabular}{lcccccc}
\hline \multicolumn{3}{c}{ Calibration } & \multicolumn{4}{c}{ Verification } \\
\hline Season & $R^{2}$ & $R_{a}^{2}$ & SN1 & SN2 & RE & $r$ \\
P10C4 & 0.331 & 0.301 & 27 & $34^{*}$ & 0.226 & $0.475^{*}$ \\
P10C9 & 0.392 & 0.365 & 24 & $35^{*}$ & 0.308 & $0.555^{*}$ \\
C2C4 & 0.457 & 0.439 & 30 & $41^{*}$ & 0.376 & $0.613^{*}$ \\
C2C3 & 0.374 & 0.360 & 31 & $36^{*}$ & 0.312 & $0.558^{*}$ \\
C2 & 0.393 & 0.380 & $35^{*}$ & $34^{*}$ & 0.326 & $0.571^{*}$ \\
\hline
\end{tabular}

* Significant $(p<0.01)$.

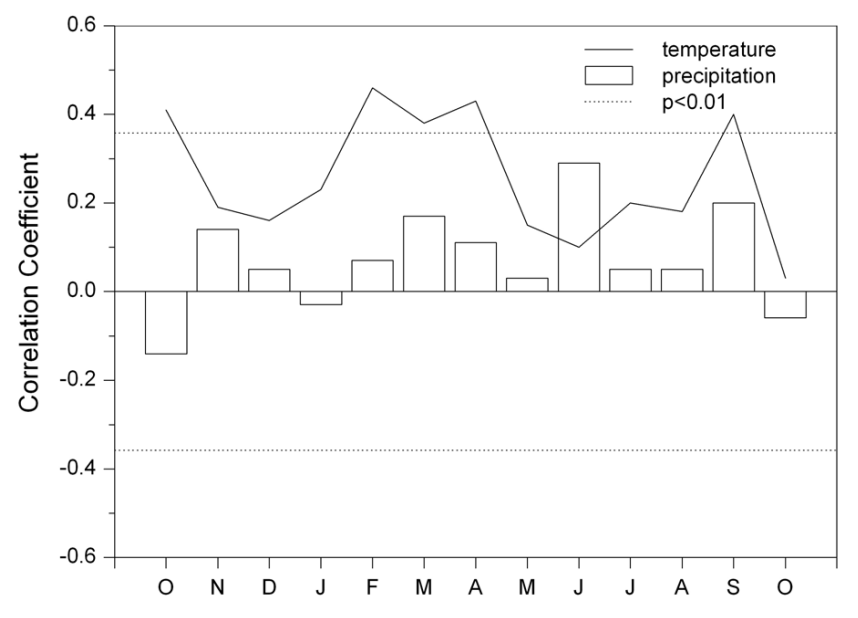

Fig. 3. Correlations between the regional chronology $(\mathrm{CB})$ and monthly temperature and precipitation from previous October to current September at Dunhua station (1953-2002).

like apparent loss of temperature sensitivity in some northern forests (D'Arrigo et al., 2008; Briffa et al., 1998), there appears to be no such shift in response at Changbai Mountain, indicating the trees' continued response to temperature.

The cold/warm periods in our reconstruction (TCBM) (Fig. 5a) are generally consistent with other temperature reconstructions in East Asia. The warm period of W1 and cold periods of $\mathrm{C} 1$ and $\mathrm{C} 2$ were all indicated by a historical documented winter-half year temperature record of East China (EC: Ge et al., 2003) (Fig. 5c) and a tree ring-based February-April temperature reconstruction of central Japan (CJ: Yonenobu and Eckstein, 2006) (Fig. 5b), although they are more than $1000 \mathrm{~km}$ away from our study site. Moreover, there are evidences from historical documents to suggest that cold climate occurred in the neighboring Heilongjiang Province during 1806-1810 and 1821-1850 (Gong et al., 1979 ), and cold winters or episodes of heavy snowfall occurred in Japan during 1807-1819 and 1826-1836 (Fukaishi 


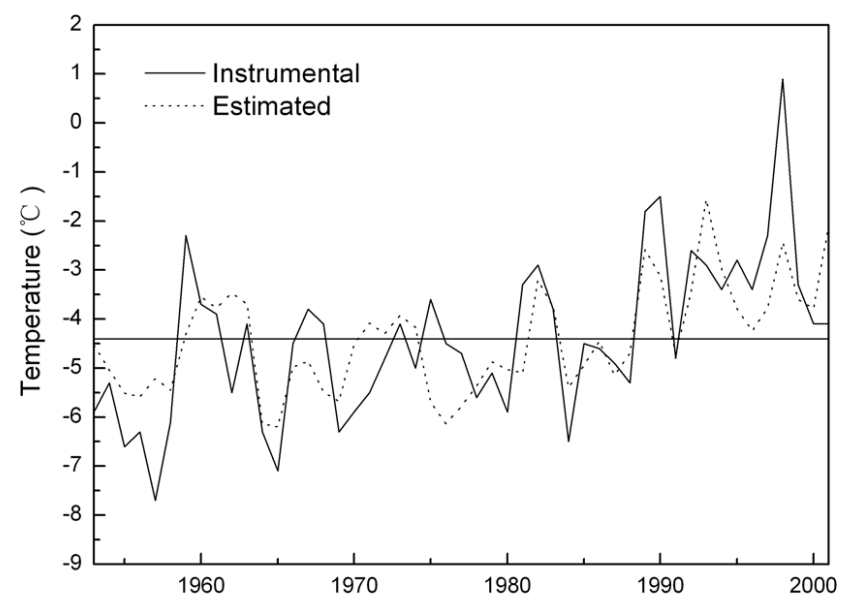

Fig. 4. Comparison between the instrumental and reconstructed February-April temperatures at Dunhua Station.

and Tagami, 1992). Despite their differences in lengths and magnitudes, the warm period $\mathrm{W} 1$ agrees well with the EC record. In addition, $\mathrm{C} 3$ is detected in both $\mathrm{EC}$ and $\mathrm{CJ}$ records, although it is not as long as in those studies. The cold period of 1910-1940s (C4) is consistent with the low FebruaryApril temperature in CJ. Overall, these agreements suggest that our reconstruction is of good reliability, and captures regional cold/warm variations in EA on the decadal scale. A former reconstruction of January-April maximum temperature for the Changbai area was based mainly on Larix olgensis and Picea jezoensis (Shao and Fan, 1999). However, due to the removing of persistence by autoregressive modeling (Cook and Kairiukstis, 1990) of their tree-ring data, little low-frequency variations were retained in the record for a comparison with the current reconstruction.

In addition, the coldest years $1837-1839$ in the past 250 years in northeast China were also indicated in other proxy records of EA. In Japan, the winters were also cold in 18381839 (Yonenobu and Eckstein, 2006), and the occurrence frequencies of the winter monsoon weather patterns are high (Hirano and Mikami, 2008). Tree-ring records in central Korea indicate that it was cool in early summer during 18351844, with the lowest temperatures occurring in 1841-1842 (Choi et al., 1994). The consistency implies that there may be synchronous occurrence of extremely cold winters or even cool summers in EA.

We correlated the reconstructed temperature against the EAWM index (EAWMI), which is based on the sum of zonal SLP differences $\left(110^{\circ} \mathrm{E}-160^{\circ} \mathrm{E}\right)$ computed at $10^{\circ}$ intervals over $10-60^{\circ} \mathrm{N}$ (Guo, 1994). The reconstructed temperature correlates with the winter (December-February) EAWMI at $r=-0.342(p<0.001)$ over the period 1874-2000, and at $-0.503(p<0.001)$ over the period 1951-2000 (Fig. 5d). The relatively lower correlation over the whole time span may be due to the scarcity of pressure data in earlier peri-

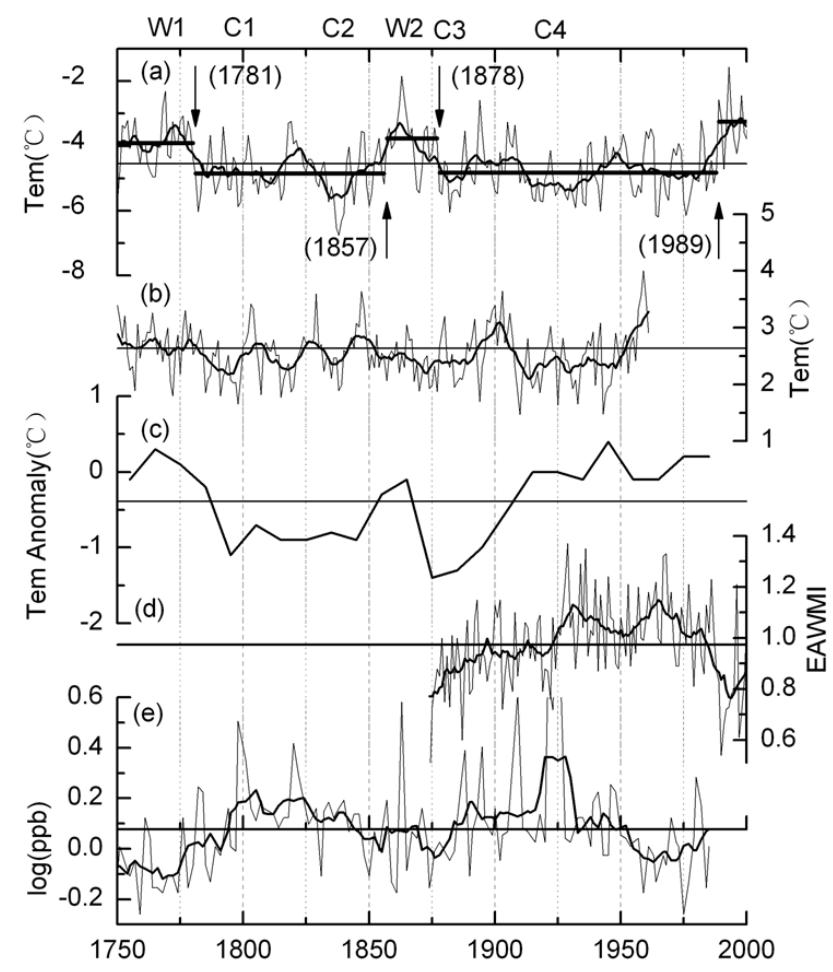

Fig. 5. Comparisons of the February-April temperature reconstruction in this study with other temperature reconstructions and East Asian Winter Monsoon (EAWM) records. (a) February-April temperature reconstruction of this study; (b) February-April temperature reconstruction in central Japan (Yonenobu and Eckstein, 2006); (c) winter-half year temperature reconstruction in East China (Ge et al., 2003); (d) East Asian Winter Monsoon (EAWM) index (Guo, 1994); (e) Non-seasalt potassium concentration (NSSK) in ice core from central Greenland (Meeker and Mayewski, 2002). The thick black curves are the 11-year moving averages and the horizontal lines are the long-term means. The years identified as shifts of the temperature reconstruction in this study are marked by arrows, and their long-term means are represented by the horizontal thick lines in (a).

ods, which introduced uncertainties in the EAWMI. Strong EAWM years are characterized by a frequent occurrence of cold surges that brings cold air from the Siberian/Mongolian High ( $\mathrm{SH}$ ), thus producing the below-normal temperatures in the study area (Ding, 1990; Guo, 1994; Jhun and Lee, 2004; Yin, 1999). In addition, the shift identified at 1989 in our reconstruction is also consistent with the weakening of EAWM in the late 1980s (D'Arrigo et al., 2005; Nakamura et al., 2002; Tsunoda et al., 2006; Wang and Jiang, 2006).

The relationship between the reconstructed FebruaryApril temperature in the Changbai Mountain area and the EAWM is also verified by other proxy records. The $\mathrm{SH}$ is the source area of EAWM, and its intensity is significantly positively correlated with the EAWM intensity, thus the intensity 
of SH can also be used to indicate the intensity of EAWM (Guo, 1994; Jhun and Lee, 2004; Wu and Wang, 2002). The non-seasalt potassium (NSSK) in the ice core from central Greenland was suggested to be transported from central Asia, and has been used to reconstruct the spring (March-May) SH intensity (Meeker and Mayewski, 2002). The high/low NSSK content variations are in good match with cold/warm periods in our reconstruction (Fig. 5e). Moreover, D'Arrigo et al. (2005) have developed a difference index between the normalized SH index and North Pacific index based on treering records collected over broad regions of Eurasia and northwest America. Although this index provides more information on the interannual variability of EAWM, it also demonstrates stronger winter monsoon during 1825-1851 and 1920-1940s, which is in agreement with the cold periods ( $\mathrm{C} 1$ and $\mathrm{C} 4)$ of our reconstruction. In addition, $\mathrm{C} 2$ is consistent with a culmination of the EAWM from $\sim 1825$ to 1841 recorded by historical documents in Japan (Hirano and Mikami, 2008).

\section{Conclusions}

In this study, we reconstructed a new February-April temperature record based on tree-ring widths of Korean Pines from the Changbai Mountain in Northeast China, which revealed variations at interannual to multi-decadal scales over the past 250 years. The series captures well the recent warming trend in northeast China. The cold/warm periods identified in the reconstruction are in good agreement with other reconstructions in East Asia, suggesting that these are significant periods with regional implications. In addition, our reconstruction shows negative correlations with instrumental or proxy-based EAWM intensity records. The known regime shift of EAWM in the late 1980s is captured in the reconstruction, and similar shifts have occurred over the past 250 years. On the whole, these comparisons suggest that our reconstruction is of good reliability and may also be used as an indicator of the EAWM intensity. Hence, more efforts should be paid to extend the reconstruction by collecting more old trees or excavated wood samples buried under the volcanic ashes.

Acknowledgements. We thank Hitoshi Yonenobu, Rosanne D'Arrigo and Paul A. Mayewski for providing their data for comparison. We also thank Dian-Feng Qiao, Lei Huang, Yan Xu and Yong-Xiang Zhang for their assistance. Thanks were also given to the three anonymous referees for their helpful and constructive suggestions and comments on the MS. This research was funded by the Chinese Academy of Sciences (KZCX2-YW-315) and the National Natural Science Foundation of China (40771211 and 40890051).

Edited by: V. Masson-Delmotte

\section{References}

Brauning, A.: Combined view of various tree ring parameters from different forest habitats in Tibet for the reconstruction of seasonal aspects of Asian Monsoon variability, Palaeobotanist, 50, 1-12, 2001.

Briffa, K. R., Schweingruber, F. H., Jones, P. D., Osborn, T. J., Shiyatov, S. G., and Vaganov, E. A.: Reduced sensitivity of recent tree-growth to temperature at high northern latitudes, Nature, 391, 678-682, 1998.

Briffa, K. R., Osborn, T. J., and Schweingruber, F. H.: Large-scale temperature inferences from tree rings: a review, Global. Planet. Change, 40, 11-26, 2004.

Chabot, B. F. and Hicks, D. J.: The ecology of leaf life spans, Annu. Rev. Ecol. Syst., 13, 229-259, 1982.

Choi, J. N., Park, W. K., and Yu, K. B.: Central Korea temperature changes reconstructed from tree rings of subalpine conifers: 1635 AD to 1990, Dendrochronologia, 12, 33-43, 1994.

Cook, E. R. and Kairiukstis, L. A.: Methods of dendrochronology: applications in the environmental sciences, Kluwer Academic Publishers, Dordrecht, 394 pp., 1990.

Cook, E. R., Meko, D. M., Stahle, D. W., and Cleaveland, M. K.: Drought reconstructions for the continental United States, J. Climate, 12, 1145-1162, 1999.

D’Arrigo, R., Jacoby, G., Pederson, N., Frank, D., Buckley, B., Nachin, B., Mijiddorj, R., and Dugarjav, C.: Monogolian treerings, temperature sensitivity and reconstructions of Northern Hemisphere temperature, Holocene, 10, 669-672, 2000.

D’Arrigo, R., Wilson, R., Panagiotopoulos, F., and Wu, B. Y.: On the long-term interannual variability of the east Asian winter monsoon, Geophys. Res. Lett., 32, L21706, doi:21710.21029/22004GL022271, 2005.

D'Arrigo, R., Wilson, R., Liepert, B., and Cherubini, P.: On the 'Divergence Problem' in Northern Forests: A review of the treering evidence and possible causes, Global. Planet. Change, 60, 289-305, 2008.

Ding, Y.: Build up, airmass transformation and propagation of the Siberian High and its relation to cold surge in east Asia, Meteor. Atmos. Phys., 44, 281-292, 1990.

Fritts, H. C. (Ed.): Tree Rings and Climate, Academic Press, London, 567 pp., 1976.

Fukaishi, K. and Tagami, Y.: An attempt of reconstructing the winter weather situations from $1720-1869$ by the use of historical documents, in: Proceedings of the International Symposium on the Little Ice Age Climate, Tokyo Metropolitan University, Tokyo, 25-27 September 1991, 194-201, 1992.

Ge, Q. S., Zheng, J. Y., Fang, X. Q., Man, Z. M., Zhang, X. Q., Zhang, P. Y., and Wang, W. C.: Winter half-year temperature reconstruction for the middle and lower reaches of the Yellow River and Yangtze River, China, during the past 2000 years, Holocene, 13, 933-940, 2003.

Gong, G. F., Chen, E. J., and Wen, H. R.: The climatic fluctuations in the Heilongjiang province, China, Acta Geographica Sinica, 34, 129-138, 1979.

Guo, Q.: Relationship between the variations of East Asian Winter Monsoon and temperature anomalies in China, Quaterly Journal of Applied Meteorology, 5, 218-225, 1994.

Havranek, M. and Tranquillini, W.: Physiological processes during their winter dormancy and their ecological significance, in: Ecophysiology of coniferous forest, edited by: Smith, W. K. and 
Hinkley, T. M., Academic Press, New York, USA, 95-124, 1995. Hirano, J. and Mikami, T.: Reconstruction of winter climate variations during the 19th century in Japan, Int. J. Climatol., 28, 14231434, 2008.

Holmes, R. L.: Computer-assisted quality control in tree-ring dating and measurement, Tree-Ring Bull., 43, 69-78, 1983.

Jhun, J. G. and Lee, E. J.: A new East Asian Winter Monsoon index and associated characteristics of the winter monsoon, J. Climate, 17, 711-726, 2004.

Liang, E. Y., Shao, X. M., and Qin, N. S.: Tree-ring based summer temperature reconstruction for the source region of the Yangtze River on the Tibetan Plateau, Global. Planet. Change, 61, 313320, 2008.

Liang, E. Y., Shao, X. M., and Xu, Y.: Tree-ring evidence of recent abnormal warming on the southeast Tibetan Plateau, Theor. Appl. Climatol., 98, 9-18, 2009.

Liu, X., Shao, X., Zhao, L., Qin, D., Chen, T., and Ren, J.: Dendroclimatic temperature record derived from tree-ring width and stable carbon isotope chronologies in the middle qilian mountains, China, Arct. Antarct. Alp. Res., 39, 651-657, 2007.

Meeker, L. D. and Mayewski, P. A.: A 1400-year high-resolution record of atmospheric circulation over the North Atlantic and Asia, Holocene, 12, 257-266, 2002.

Michaelsen, J.: Cross-validation in statistical climate forecast models, J. Climate Appl. Meteorol., 26, 1589-1600, 1987.

Nakamura, H., Izumi, T., and Sampe, T.: Interannual and decadal modulations recently observed in the Pacific storm track activity and east Asian winter monsoon, J. Climate, 15, 1855-1874, 2002.

Pederson, N., Cook, E. C., Jacoby, G., Peteet, D. M., and Griffin, K. L.: The influence of winter temperatures on the annual radial growth of six northern range margin tree species, Dendrochronologia, 22, 7-29, 2004.

Rodionov, S. N.: A sequential algorithm for testing climate regime shifts, Geophys. Res. Lett., 31, L09204, doi:09210.01029/02004GL019448, 2004.
Shao, X. M., and Wu, X. D.: Reconstruction of climate change on Changbai Mountain, northeast China using tree-ring data, Quaternary Sci., 76-85, 1997.

Shao, X. M. and Fan, J. M.: Past climate on west sichuan plateau as reconstructed from ring-widths of dragon spruce, Quaternary Sci., 81-89, 1999.

Stokes, M. A. and Smiley, T. L.: An Introduction to Tree Ring Dating, University of Chicago Press, Chicago, USA, 73 pp., 1968.

Tsunoda, T., Kawahata, H., Suzuki, A., Minoshima, K., and Shikazono, N.: Winter sea surface temperature variations based on coral oxygen isotope record from Ishigaki Island, the Ryukyus, Japan and transition of its dominant climate factor with 1988/1989 climate regime shift, Geochim. Cosmochim. Ac., 70, A657-A657, 2006.

Wang, H. and Jiang, D.: A new East Asian Winter Monsoon intensity index and atmospheric circulation comparison between strong and weak composite, Quaternary Sci., 24, 19-27, 2006.

Wigley, T. M. L., Briffa, K. R., and Jones, P. D.: On the average value of correlated time series, with applications in dendroclimatology and hydrometeorology, J. Clim. Appl. Meteorol., 23, 201-213, 1984.

Wu, B. Y. and Wang, J.: Winter Arctic Oscillation, Siberian High and East Asian Winter Monsoon, Geophys. Res. Lett., 29, 1897, doi:1810.1029/2002GL015373, 2002.

Yin, Z. Y.: Winter temperature anomalies of the North China Plain and macroscale extratropical circulation, Int. J. Climatol., 19, 291-308, 1999.

Yonenobu, H. and Eckstein, D.: Reconstruction of early spring temperature for central Japan from the tree-ring widths of Hinoki cypress and its verification by other proxy records, Geophys. Res. Lett., 33, L10701, doi:10710.11029/12006GL026170, 2006.

Zhu, H. F., Zheng, Y. H., Shao, X. M., Liu, X. H., Xu, Y., and Liang, E. Y.: Millennial temperature reconstruction based on tree-ring widths of Qilian juniper from Wulan, Qinghai Province, China, Chin. Sci. Bull., 53, 3914-3920, 2008. 